\title{
Sobre um caso de tumor da base do cranio
}

\author{
Lição de clinica propedeutica feita aos alumnos do quarto anno geral \\ PELO PROF. \\ A. DE ALMEIDA PRADO \\ (Lente substituto de clinica medica)
}

\begin{abstract}
Entrando hoje no estudo da propedeutica nervosa, prevaleço-me da opportunidade para vos mostrar um doente, em cujo quadro clinico vamos encontrar agrupados, uma symptomatologia complexa e rica, elementos semioticos que fazem parte de varios syndromos nervosos, permittindo, assim, encetarmos esse estudo com a feição pratica e proveitosa que o caso comporta.

O doente que vos apresento, cuja estadia na nossa enfermaria data já de cerca de vinte dias, facultando esse já relativamente longo tempo de estagio hospitalar observação demorada, alicerçada em pacientes e reiterados exames, aqui entrou ataxico, titubeante na marcha, com os symptomas da serie cerebellar completos, em estado que nem de longe se assemelha ao actual. Muitos de vós, que me vistes examinal-o nos dias subsequentes ao da sua admissão, estarão certamente 'lembrados do quadro que elle então apresentava € que agora vol-o recordo apenas para salientar a evolução da molestia.
\end{abstract}

\section{ANAMNESE}

A historia anamnestica tomada nos dias de sua chegada assim se resume: antecedentes familiares de nuila importancia; paes fallecidos em edade avançaãa por molestias que não dizem respeito com a sua doença actual; ha oito mezes contrahiu cancro duro de que se tratou neste hosnital; bebia pouco, ás refeições.

\section{histgria PREGRESGA Da MOLEStía}

Ha cerca de quarenta dias começou a ser incommodaão por ficrte cephaléa, gradativamente crescente, que, de começo, o não impediu de continuar no seus mistéres de sapatoiro, procurando allivio na ingestão diaria de aspirina, que, $\in \mathrm{m}$ verdade, pouco melhorava seu estado. Vinte dias apprczimadamente após o apparecimento da cepnaléa notou que as pernas entraram a enfraquecer, difficultando-lihe a marcha e, ao mesmo tempo, começou a sentir um estado cie ebriedale a ponto tal, que, um dia, ao tentar atravessar de uma 
c. outra calçada da rua, teve um ictus passageiro, com perda de consciencia, cahindo pesadamente ao solo. Soccorrido por um amigo, foi levado para casa e acamou-se. Passou a noite atormentado por forte cephaléa e no dia seguinte amanheceu com difficuldade da palavra e com a bocca torta. Dois dias após procurou o hospital. Eis como se apresentou ao exame clinico quando foi de sua internação hospitalar.

\section{EXAME CLINICO}

Individuo moço, de 27 annos, de compleição mediana. Deitado, impressiona logo, á inspecção, a paralysia facial esquerda, typo peripherico, presentes todos os signaes decorrentes da participação paralytica dos ramos do facial superior (lagophtalmia, signaes de Bell, ide Negro, ide Legendre, ide Dupuy-Dutemps e Cestan e dos Revilliod). Cabeça constantemente voltada para a direita com contracção espasmodica dos musculos do pescoço do mesmo lado.

Em pé, alarga a base de sustentação com tendencia manifesta á queda para a direita (lateropulsão). Não ha signal de Romberg. Marcha zigzagueante, cerebellar. Desordens hypermetricas mais pronunciadas á direita. Adiadococinesia verificada nos movimentos rapidos e alternativos da mão direita. O exame da sensibiðidade na hemi-face esquerda revelou profundas alterações sensitivas no territorio do trigemeo: anesthesia tactil, thermica e dolorosa, particularmente accentuada na zona a cargo do ophtalmico. Anesthesia da cornéa; anesthesia da conjunctiva, das mucosas nasal e buccal esquerdas. Diminuição do gosto (hypogeusia) nos dois terços anteriores da metade esquerda da lingua.

o exame da funcção gustativa, que se me afigurou do maior interesse no caso, fil-o em repetidas provas com quinino, assucar etc. Para estar bem seguro de seus resultados, pedi ao Prof. Barros a applicação do electrodo de uma corrente galvanica e - afastada, assim, todas as causas de erros - pudemos reconhecer, elle e eu, uma hypogeusia manifesta nos dois terços anteriores esquerdos da lingua: o gosto do metal somente era sentido após um lapso de tempo relativamente grande, ao passo que á direita a sensação era immediata. A secreção lacrimal está presente. Reflexos tendinosos vivos. A' vista da paralysia facial e da ataxia, suspeitando a origem labyrinthica ldas perturbações do equilibrio, resolvi submetter o doente ao exame de um especialista de ouvidos.

o Dr. Schmidt Sarmento, a quem o confiei então, afóra a retracção da membrana esquerda do tympano nada achou para o lado dos apparelhos da audição e vestibular. Verificou tambem a paralysia facial peripherica e ligeiro edema da uvula e da pharynge. $O$ exame ophtalmologico, feito pelo Dr. Pereira Gomes, deu o seguinte resul- 
tado: reacções pupillares normaes (luz, accommodação, convergencia e consensual); lagophtalmia do OE. por paralysia facial correspondente; meios oculares normaes; fundos oculares: estase venosa accentuada e congestão das papillas: visão: $\mathrm{OD}$ e $\mathrm{OE}=2 / 3$.

Electro-diagnostico (Prof. Barros): Diminuição da excitabilidade faradica no territorio dos ramos inferiores e medio do facial esquerdo. Excitabilidade galvanica, normal em ambos os lados.

\section{EVOLUÇÃO}

Internado nas condições morbidas que acabo de vos expor, pondo-vos ao corrente do exame clinico praticado nos dias da entrada e do resultado de outros exames subsidiarios feitos, - a simples apresentação do doente nas condições actuaes é sufficiente para que, do cotejo, possaes inferir quanto melhorou no nosso serviço. Elle, que não podia quasi manter-se' em pé, tomado pela titubeação cerebellar, que andava mal, com a desorientação classica da marcha cerebellar, que vinha sendo atormentado por atroz cephaléa, viu pouco e pouco a regressão desses males confirmada nas melhoras actuaes.

A. que attribuir taes melhoras? Penso que só a idescompressão, obtida pela punç̧ão lombar, explica o facto. No intuito de esclarecer o diagnostico etiologico fiz, com effeito, uma puncção no doente alguns dias após a sua entrada e dahi data o desapparecimento đa cephaléa e melhoria dos symptomas cerebellares. O liquido jorrou na agulha com grande pressão. O doutorando Pennino, que escreve these sobre assumpto que se relaciona com o caso, applicando apparelho adequado estimou em 30 millimetros $\mathrm{Hg}$ a tensão rachidiana, que é, normalmente, de cerca de 10 millimetros. Havia, portanto, consideravel hypertensão craniana. O liquido cephalo-rachidiano, extrahido em quantidadé de cerca ıde 20 cc., foi examinado pelo Prof. Donati, que verificou a presença da lymphocytóse e a Wassermann positiva. A' vista desse resultado institui logo o tratamento mercurial e iodetado, mantido até hoje.

Ultimamente repeti a puncção, o liquido alcançou 15 millimetros de tensão, e o doente experimentou, em seguida, novas melhoras.

Mas, direis, porque não attribuir a evolução do caso ao tratamento e sim á descompressão? Por dois motivos: $10^{\circ}$ as melhoras ibtidas foram muito rapidas para que pudessem ser devidas ao mercurio que não actua tão promptamente; $2 .^{\circ}$ os symptomas que se attenuaram (cephaléa, ataxia, signaes de séde cerebellar) são no caso symptomas de compressão, mas de compressão indirecta, por hypertensão craniana, e não de compressão directa por obra de tumor, placa de meningite etc.; tanto é assim que os symptomas, 
que diriamos organicos - a paralysia facial e as perturbações no dominio do trigemeo - persistem, attenuados sim, mas sufficientes para serem reconhecidos por pouco que se esmiuce o caso. As melhoras são assim enganadoras; mais apparentes que reaes.

Isto posto, passemos ao exame do doente, verifiquemos os symptomas vigentes.

\section{SYMPTOMAS ACTUAES}

Já vimos, pela evolução do caso, quaes os symptomas que existem actuallmente: paralysia facial e perturbações de natureza paralytica no territorio do trigemeo.

Façamos agora, com o intuito propedeutico, a semiologia em separado desses symptomas, applicavel ao caso, sem cuidar por emquanto, do diagnostico, que fará assumpto da sua discussão.

\section{SEMIOLOGIA DA PARALYSIA FACIAL PERIPHERICA}

Esta questão comporta dois quesitos: a) como a reconhecer clinicamente? - b) como lhe diagnosticar a séde?

Ao primeiro quesito devemos responder mostrando em que differe anatomo-physiologicamente a paralysia typo peripherico, da paralysia typo central.

Deveis de estar lembrados que Dejerine distingue, nos feixes motores, duas vias principaes: a via cortico-medullar, representada pelas fibras que, promanando dos centros motores corticaes, descem até o bulbo e, após entrecruzamento, vão ter ás çolumnas cellulares motoras da medulla; a via cortico-nuclear, representada pelas fibras que provindas da zona motora, após entrecruzamento, vão tor aos nucleos motores idos nervos cranianos. A lesão das fibras faciaes comprehendida no percurso da via cortico nuclear, isto é, no percurso que vae da cortex cerebral aos nucleos intraprotuberanciaes (origens reaes do nervo), dá margem á paralysia typo central. E' a lesão do primeiro nevronio motor. A lesão do facial abaixo ldessa via, isto é, desde seu nucleo até ás ramificações mais superficiaes do nervo, dá origem á paralysia typo peripherico. E' a lesão do segundo neuronio motor, ou neuronio motor inferior.

Clinicamente a paralysia peripherica diverge da central por affectar por iguai os dois ramos do facial, o superior e o inferior, por apresentar a reaç̧ão electrica de degeneração e por se não acompanhar geralmente de hemipiegia. Sabeis tambem que ao facial superiour cabe dar motilidade aos muscuics süperciliar, crbicular e frontal, donde deduzireis facilmente os signaes reveladores da ina- 
ç̧ão desses musculos. Inactivo o superciliar, o supercilio no lado paralysado cahe, perdendo sua forma recurva natural; a paralysia do olbicular impede, por não compensar a acção correspondente do elevador palpebral, o perfeito fechamento dos olhos, dahi resultando a lagophtailmia (impossibilidade de fechar os olhos); ainda á conta da paralysia do orbicular, por mecanismos varios de musculos em esforço de substituição, corre o apparecimento dos signaes de Belli, de Dupuy-Dutemps e Cestan e de Legendre. A paralysia do frontal responde pelo apparecimento do signal de Negro.

Applicando ao nosso doente, que apresentou no inicio todos estes signaes, os elementos expostos para o descrime semiotico entre as duas formas de paralysias, vejamos o que delles se deve concluir. Já na attitude de repouso lhe notareis a asymetria facial, bocca repuchada para o lado direito; aberta toma a forma obliqua oval.

Mandando-o fechar os olhos em conjuncto ou em separado, executa o acto actualmente bem, donde concluimos que a lagophtalmia já não existe e bem assim o signal de Revilliod (impossibilidade de fechar o olho do lado paralysado separadamente). Mandando-o, como ora faço, olhar ao alto, no maximo, vemos que o globo ocular da lado esquerdo soffre maior rotação para cima (signal de Negro). O signal de Dupuy-Dutemps e Cestan, que elle apresentou muito bem, agora ausente, é o seguinte: mandando-se o doente ollhar fixo para baixo a palpebra superior do lado paralysado vem para baixo igualmente; não acompanha, no emtanto, nesse movimento, a palpebra do lado são: isto é, fica-lhe num nivel superior. Si, nesse momento mandarmos o doente fechar os olhos com vigor, verificaremos que a palpebra do lado doente se eleva de modo evidente e tanto mais, quanto maior for o gráu de paralysia do orbicular. Ordenando ao doente de fechar os olhos e impedindo o movimento de abaixamento da palpebra superior esquerda, como estou fazendo agora, haveis de reparar na rotação involuntaria do globo ocullar para cima e para fóra. E' o signal de Bell, especificado claramento no caso. Mandando-se o doente cerrar as palpebras com força e tentandose ao depois descerral-as, encontra-se maior resistencia no lado esquerdo (signal de Legendre) como podereis verificar pessoalmente.

Da exposicão e das pesquizas semioticas agora feitas, podemos inferir que a paralysia facial soffreu ligeira regressão (desapparecimento da lagophtamia, do signal de Dupuy-Dutemps e Cestan etc.), mas que permanece ainda perfeitamente reconhecivel em seus sym. ptomas capitaes (desvio da bocca, signaes de Bell e de Negro etc.). Podemos, ainda mais, a despeito do exame electrico não ter dado a reacção degenerativa, concluir pela natureza peripherica da paralysia. 
Vejamos agora o segundo quesito proposto: como lhe diagnosticar a séde?

o diagnostico da séde decorre integralmente da anatomia do nervo. Trazeis do estudo da anatomia o perfeito conhecimento do trajecto do facial, desde os nucleos intraprotuberanciaes de origem cie suas fibras, as quaes, após terem descripto uma alça em derredor cio nucleo do VI par, emergem no sulco bulbo-protuberancial, até sua dichotomisação peripherica, que recordarei daqui ha pouco. A visinhança dos nucleos do facial esquerdo e direito, a proximidade desses nucleos do feixe pyramidal e das vias sensitivas, a disposição das fibras faciaes em relação ao nucleo do VI par na protuberancia, €xplicam porque as paralysias nucleares do facial são quasi sempre bilateraes, associadas ás do VI par muitas vezes e, não raro, acompanhadas de perturbações motoras ou sensitivas de typo hemiplegico. Emergindo do sulco bulbo-protuberancial, procuram as fibras ddo facial o conducto auditivo-interno, atravessam-no intimamente unidas ao nervo auditivo; sahindo do conducto auditivo interno ganha $\checkmark$ facial $o$ aqueducto de Fallopio, segue-lhe itodas as inflexões até o buraco estylo-mastoideo. Importa sobremaneira conhecer para 0 diagnostico topographico as relações do facial com o trigemeo, mantidas á custa de ramos anastomoticos, que partem do primeiro no seu percurso dentro do aqueducto de Fallopio. Desde seus nucleos de origem até seu primeiro ponto de inflexão no aqueducto, não dá o ffacial collateral nenhum; allcançado esse ponto, que é represientado nesta gravura pela lettra G (figura I, G), encontramos o ganglio geniculado donde partem dois ramos collateraes: o grande e o requeno nervo petreos superficiaes. $O$ grande petreo superficial, como demonstra melhor esta segunda gravura (figura II) vae anastomosar-se com um ramo do trigemeo, formando o nervo lacrimal; abaixo do ganglio geniculado o facial emitte um ramo destinado ao musculo do estribo; finalmente, mais abaixo, vemos destacar-se a corda do tympano, que, após fusão com o nervo lingual, ramo do trigemeo, fornece sensibilidade gustativa aos dois terços anteriores da lingua. Dessas noções anatomicas resultam as seguintes conclusões: lesado o facial no aqueducto de Fallopio antes do ganglio geniculado, isto é, antes ide dar ramos collateraes, os symptomas gerados serão os mesmos de uma lesão na base do cerebro: paralysia facial total; ao nivel do ganglio geniculado a lesão provocará desordens lacrimaes — ausencia da secreção lacrimal que estudaremos melhor quando falarmos da semiologia do trigemeo; abaixo do ganglio geniculado, por interessar o musculo do estribo, haverá desordens auditivas - hyperacusia segundo uns, hypoacusia segundo a maioria; - mais abaixo ainda, interessando a corda do tympano, haverá anesthesia gustativa nos dois 


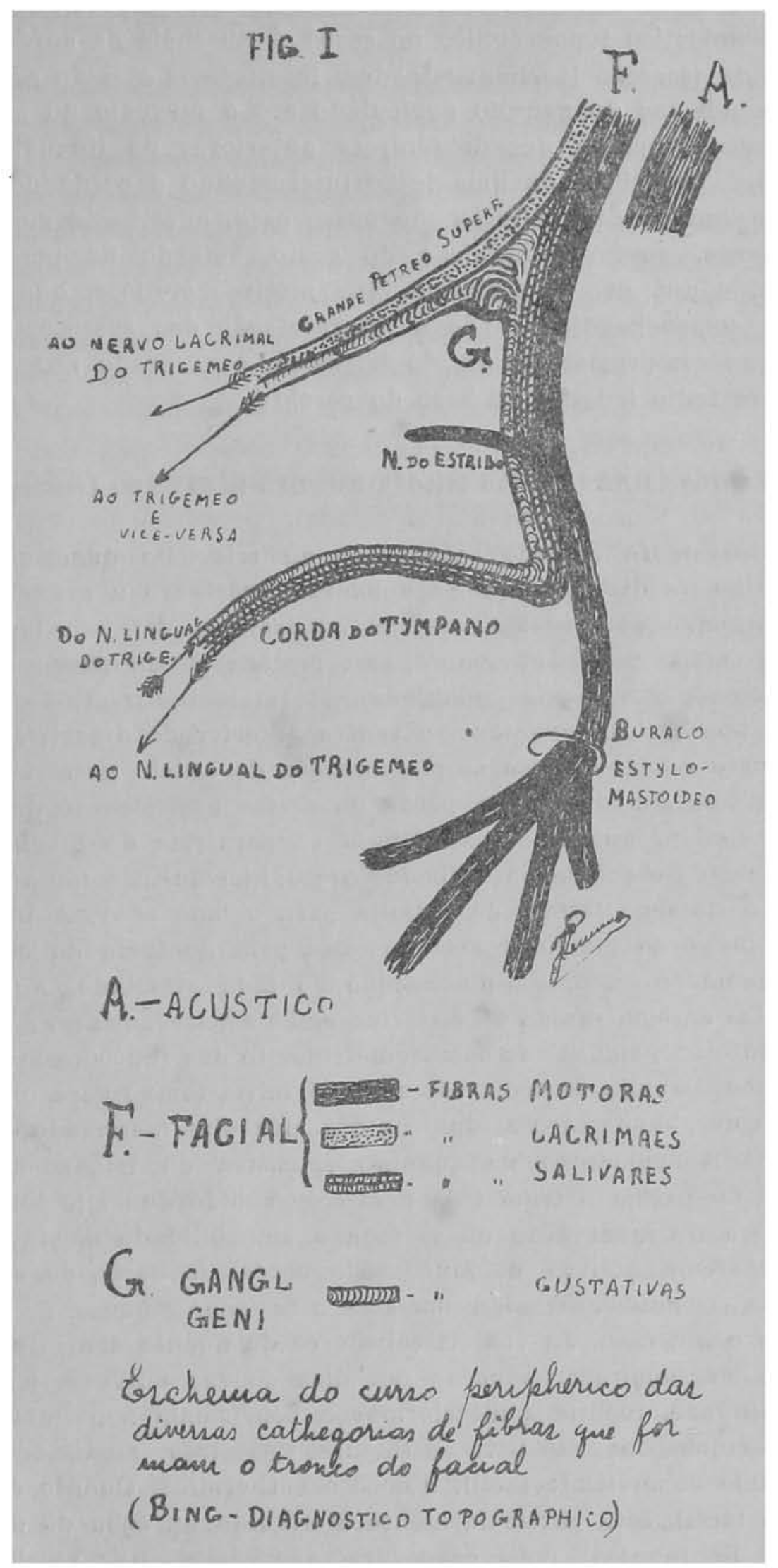


terços anteriores da lingua. Que elementos colhemos do exposto para o diagnostico topographico no caso? A ausencia da surdez e a presença de secreção lacrimal impedem localizemos a lesão em todo o espaço que vae do ganglio geniculado até o musculo do estribo. A hypogeusia, notada nos dois terços anteriores da lingua, seria favoravel á hypothese de uma lesão interessando a corda do tympano; mas, notae bem, não ha, no nosso caso, anesthesia gustativa propriamente, porém diminuição do gosto, retardo na percepção gustativa, o que não é o mesmo. Por motivos clinicos, que serão melhores comprehendidos após a interpretação doș symptomas referentes ao compromettimento do trigemeo," sou levado a localizar no caso vertente a lesão na base do cerebro.

\section{SEMiologia das PERTURbações SENsitivas (trigemeo)}

Preliminarmente cumpre reconhecer no trigemeo duas porções funccionalmente distinctas: a pequena raiz motora e a grande raiz sensitiva, tendo ambas suas origens apparentes, uma ao lado da outra, em plena protuberancia. A raiz motora ou do nervo mastigardor acciona os musculos mastigadores (masseter, temporal, pterigoideos etc.); o mylohyoideo, o ventre anterior do digastrico etc. Clinicamente reconhecem-se os phenomenos de ordem paralytica da porção motora do nervo pela perda de certos movimentos de lateralidade e de propulsão da mandibula (a paralysia do pterigoideo externo impede a propulsão do condylo e dahi resulta a impossibilidade da deslocação lateral da maxilla para o lado são). A inacção do masseter e do temporal exteriorisa-se pela ausencia da contraç̧ão muscular no acto da mastigação no lado affectado. Aquelles movimentos e a contracção masseterina estão conservados no doence; não ha, portanto, signaes de compromettimento das funcções motoras do trigemeo. Demais, si assim não fôra, já havia tempo para o apparecimento de phenomenos atrophicos dos musculos mastigadores.

Passemos á exploração da funcção sensitiva do trigemeo. Nas lesôes que attingem o tronco do nervo - sabido que elle tem sob sua esphera de innervação quasi toda a sensibilidade da face, da mucosa das conjunctivas, da mucosa da bocca, do nariz, da cornéa etc. - a anesthesia dessas regiões será o facto dominante. E' o que vemos no nosso caso. Já vos fiz sabedores de quanto era intensa a anestehsia na hemiface esquerda nos dias de sua entrada. Exames da sensibilidade, repetidos ulteriormente, confirmam a permanencia dessas perturbações sensitiva attinentes ás tres modlidades da sensibilidade superficial: tactil, dolorosa e thermica. Quanto á sensibilidade tactil, está particularmente diminuida na zona de destribuição do ophtalmico; mais para fóra, nas regiões que recebem a 
innervação dos ramos maxillar superior $\theta$ inferior, existe retardo na percepcão tactil e erro de localização.

A analgesia é tambem mais apreciavel no territorio do ophtalmico: a picada de um alfinete não provoca, como acabaes de ver, reacção alguma dolorosa. A thermoanesthesia reconhece-se na impossibilidade de accusar o doente a sensação de frio ou de calor, cuando se lhe applica, alternativamente, como agora estou fazendo, dois tubos contendo agua fria ou quente. Só depois de uma excitação prolongada e dando-se grande extensão ao contacto do excitante thermico com a pelle, elle póde accusar a impressão thermica recebida. Verificamos, ao demais, anesthesia da cornéa e da conjunctiva. Excitando-se-lhe a mucosa nasal esquerda por meio de um tampão de algodão embebido em ammoniaco vemos que a manobra, desagradabilissima em condiç̃es normaes, é perfeitamente tolerada. Provoca, no entretanto, lacrimejamento do olho correspondente como vedes, provando que existe diminuição da sensibilidade nasal e que a secreção lacrimal está normal.

De pósse dessas noções semioticas onde localizar a lesão do trigemeo no caso vertente?

Ainda aqui, a exemplo do que fizemos no estudo da semiologia do facial, torna-se necessaria uma rapida recapitulação anatomica. Sahidas da protuberancia, as duas raizes do trigemeo tomam a direcção da cavidade de Meckel, loja fibrosa formada a expensas da dura-mater, occupando a parte mais interna do rochedo; uma vez alcançada a cavidade de Meckel a raiz sensitiva vae ter ao ganglio de Gasser e após havel-o atravessado, expande-se em tres ramos terminaes: o nervo ophtalmico, o nervo maxillar superior e o nervo maxillar inferior. Este ultimo entra em connexão com a raiz motora do trigeneo tornando-se assim um nervo mixto. O glanglio de Gasser mantem estreitas relações de visinhança com o III, IV e VI pares cranianos ao nivel do seio cavernoso, immediatamente contiguo á cavidade de Meckel.

Ora, si nós para completarmos a descripção anatomica mencionarmos a existencia de fibras de natureza sympathica no ganglio de Gasser - fibras dilatadoras da pupilla - que vão ter, por intermedio do nervo ophtalmico ao ganglio ciliar - teremos resumido a feição clinica das lesões do trigemeo que interessa o ganglio de Gasser. Sobre haver nestes casos a anesthesia, já mencionada, como symptomas accessorios, de compressão, haverá a participação forçada dos nervos visinhos - paralysias do III, IV e VI pares - na scena mórbida, associadas á phenomenos, sejam já irritação mydriase, exophtalmia etc. — do sympathico, sejam já de destruição - myose, enophtalmia etc. - O diagnostico topographico dessa 
localização se apoiará nos elementos collhidos no terreno anatomo rhysiologico.

De grande interesse diagnostico são tambem as alterações que se passam na secreção lacrimal. Já, a proposito do facial, vos disse que o nervo grande petreo superficial forma, após anastomose com um ramo do trigemeo, o nervo lacrimal. E' no ganglio esphenopalatino que o nervo grande petreo alcança anastomosar-se com o trigemeo; a via completa da secreção lacrimal será assim representada: nervo grande petreo superficial, ganglio espheno-palatino (ou ciliar), nervo temporo-malar e, finalmente, a anastomose que o ultimo envia ao nervo lacrimal. A abolição da secreção lacrimal indica, pois, lesão do ganglio espheno-palatino, ou de qualquer outro ponto que lhe fique nas cercanias, na via descripta, comprehendida no traço negro do presente eschema (figura II). Por interessar o

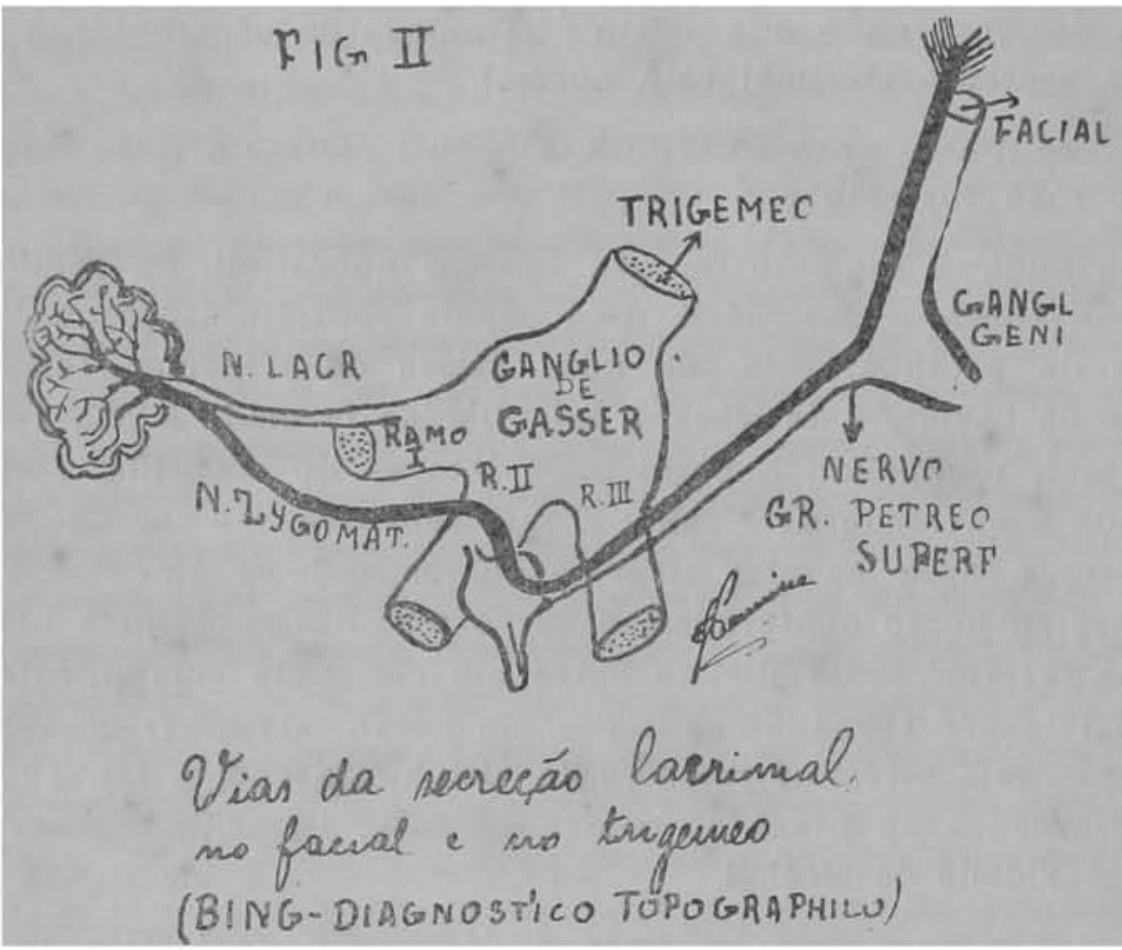

percurso dessa mesma via no ganglio geniculado - ponto de destaque do grande petreo no trajecto do facial - póde uma parallysia facial trazer a suppressão do curso das lagrimas.

Koester (1) reuniu onze casos de paralysia facial produzida por lesão no ganglio geniculado, ou em suas crrcumjacencias, acom’anhada da abolição lacrimal do mesmo lado.

(1) RAYMOND - Leçons sur les maladies du systéme nerveux tomo VI 
Outro ponto interessante para o diagnostico topographico diz com as fibras para a percepção gustativa nos dois terços anteriores da lingua.

Disse-vos que a sensibilidade do gosto nos dois terços anteriores da lingua é fornecida pelo nervo, que resulta da fusão da corda do tympano com o lingual, ramo do trigemeo, e ainda aqui vemos, como para a funcção lacrimal, uma mesma funç̧ão assegurada pelo concurso dos dois nervos, mercê da anastomose trigemino-facial. Dest'arte póde a ageusia nos dois terços anteriores da lingua occorrer por lesões que interessem esses nervos, separadamente, desde que lesem os ramos dessa anastomose.

Ha um outro facto, evidente no nosso caso, sobre o qual chamo vossa attenção, por me parecer ainda pouco explorado e que vem enriquecer a semiologia das affecções do trigemeo. Refiro-me á resquiza do reflexo oculo-cardiaco. E' este um reflexo da sensibilidade profunda cuja via centripeta é representada pelo trigemeo e cuja via centrifuga pelo pneumogastrico. A interrupção do arco reflexo em qualquer ponto de seu percurso trará, como consequencia inevitavel, a abolição do reflexo. Isto, que, a priori, já podiamos suspeitar, encontrou ampla confirmação na pesquiza do reflexo em nosso doente: do lado direito manifestou-se a queda habitual do pulso (de 8 a 10 pulsasões por minuto) e no esquerdo permaneceu c pulso inalterado. A pesquiza do reflexo foi feita muitas vezes, sempre com eguaes resultados, como pódem attestar alguns de vós, aquelles que me ajudaram na contagem do pulso. Corollario desse facto, embora de consequencias oppostas, será o incremento do reflexo oculo-cardiaco, computado na intensidade da reacção vagotonica nas lesões irritivas (nevalgia facial essencial) do trigemeo.

\section{DIAGNOSTICO}

Senhores:

Si até aqui vim vos entretendo miudamente com a semiologia dos nervos affectados no nosso caso, foi menos pela necessidade de esclarecer o diagnostico do que para aproveitar a occasião, que se me deparou opportuna, para dar balanço aos recursos que a propedeutica nos proporciona em casos taes.

Abandonando o ponto de vista estrictamente regionalista a que nos cingimos até agora, encarando o caso clinico sob seu aspecto geral, o diagnostico sobremaneira se esclarece.

Do que ficou exposto deflue, como unica noção de séde aproveitave' ao caso, a existencia da hypogeusia nos dois terços anteriores esquerdos da lingua. Vimos que tanto a lesão do facial abaixo da corda do tympano, como a do trigemeo no tronco commum do nervo, nas proximidades do ganglio esphero-palatino ou no proprio 
nervo lingual, pódem produzil-a. Mas a lesão do facial na corda do tympano nunca explicaria as pertubações na esphera do trigemeo, que constituem a symptomatologia fundamental do doente, e viceversa, a lesão dos ramos do trigemeo abaixo do ganglio de Gasser seria insufficiente para explicar a paralysia facial. Si, por outro lado, dada a concomitancia, a simultaniedade dos symptomas, somos obrigados a reconhecer-lhes a unidade causal, tudo por fim se resumirá em encontrar um sitio onde uma localização morbida póssa attingir ao mesmo tempo os dois nervos em jogo. Posta nesse pé a questão incidiremos em duas hypotheses: será por lesão central ou reripherica?

Já a respeito do facial ficou dito que as suas lesões centraes se acompanham sempre de perturbações outras da motalidade ou da sensibilidade de typo hemiplegico. O mesmo se dirá em relação ao trigemeo: as interrupções supranucleares de suas vias originam syndromos sensitivos controlateraes em virtude da decussação de suas fibras. A impossibilidade de serem attingidas ao memo tempo as fibras supranucleares do facial e do trigemeo, sem acarretar profundas desordens sensitivo-motoras, exclue por completo a hypothese de uma lesão central. A mesma argumentação subsiste quanto á hypothese de uma lesão nuclear dos dois nervos em questão, sem falarmos já no que ha de caracteristicamente peculiar ás paralysias nucleares de um e outro nervo: hemiplegia alterna, typo MillardGübler para o facial; anesthesia que, á semelhança do que occorre com os nervos sensitivos da medulla, tem uma topographia especial, diversa da anesthesia peripherica, para o trigemeo. Si por outro lado ficou demonstrado que, localizada a lesão em todo o percurso do facial que vae do conducto auditivo interno até sua ramificação terminal, ella, por si só, agindo como causa unica, não poderá de forma alguma explicar os symptomas na esphera de acção dos dois rervos interessados, fica tambem excluida esta segunda hypothese. Resta a hypothese, cabivel no caso, de uma lesão na base do cranio accommettendo a porção sensitiva do trigemeo e o facial, ao nivel de suas raizes apparentes, região em que esses nervos são separados por um espaço relativamente exiguo, capaz de ser cccupado por um tumor de dimensões não insolitas.

Admittida a existencia do tumor da base fica legitimada toda symptomatologia do doente, inclusive a hypogeusia, pois que os tumores desta séde pódem trazel-a como elemento symptomatico. Nas destruições do tronco do nervo (trigemeo) o gosto é attingido nos dois terços anteriores da lingua (Bing (1), Stewart (2), Leube

(1) BING - Diagnóstico topográfico de las enfermedades del cerebro y de la medula - 1911.

(2) STEWART - Diagnostic des maladies nerveuses - 1910. 
(3). Mas não o é tão intensamento como quando lesada a corda do tympano, não ha precisamente anesthesia gustativa, ha diminuição da percepção gustativa, hypogeusia verdadeira, como no nosso caso. o diagnostico parece-me assim bem fundamentado. A unica objeç̧ão que se lhe poderia fazer seria a seguinte: um tumor localizado na base do cerebro, compromettendo o facial e o trigemeo num individuo que apresentou symptomas cerebellares, é evidentemente da região do angulo ponto-cerebellar; nessas condições como explicar: a) a ausencia da surdez - symptoma obrigatorio nesses tumores - em virtude da contiguidade do auditivo ao facial na base do cerebro? b) a compressão do pendunculo cerebellar medio traduz-se por symptomas que, de ordinario, se manifestam do mesmo lado da lesão nos tumores daquella séde e que, no caso vertente, foram observados no lado opposto ao agente causal, visto como os symptomas directos - paralysia facial e trigemina - são á esquerda e os cerebellares - hypermetria, lateropulsão - predominaram á direita. Qual a razão dessa anomalia? Ao primeiro argumento cumpre objectar que se não trata propriamente de um tumor do anguloponto-cerebellar, tumor do acustico, denominação que bem lhe define a essencia, mas de um tumor primitivamente do trigemeo typo trigemeo na classificação de Hartmann — de séde mais pprotuberancial que cerebellar, verdadeiro tumor da base do cranio, extradural, em cujo guadro clinico, si a surdez bem póde compa:ecer, nada maravilha a sua ausencia, attenta a distancia que separa c V do VIII par. Demais o compromettimento dos nervos icranianos nas affecções da base parece depender mais directamente da natureza do processo morbido do que propriamente da séde; assim é que no proprio tumor ponto-cerebellar, no qual o VIII par é sempre interessado, o trigemeo é muito mais vezes attingido que o facial, não obstante ser muito maior a distancia que o separa do acustico. No que toca á segunda parte da objeç̧ão o desvio da regra vem mais confirmar do que infirmar o diagnostico: os symptomas cerebellares correm á conta da hypertensão craniana, não são symptomas directos de compressão do pedunculo cerebellar medio, como o são na localização ponto-cerebellar. Que esta deve ser a interpretação exacta dos factos, prova-o de sobejo o desapparecimento dos symptomas cerebellares após a punção lombar, de effeitos descompresivos immediatos, pondo a descoberto pelo sublata causa tollitur effectus, o nexo causal que os liga. E' si assim é, nada admira fossem controlateraes os resultados da hypertensão, uma vez que ella é capaz de se fazer sentir em todo o encephallo, manifestando-se, ora sobre a desconcertante apparencia de lesão cerebral em fóco - pseudo

(3) LEUBE - Diagnostico differenziale delle mallatie interne, 1908. 
tumor -, ora realisando o quadro de uma affecção medullar pseudo tabes - quando persistente e muito intensa. Observações bastante numerosas registam a possibilidade do apparecimento, por uma pathogenia estrictamente mecanica e inteiramente filiada á hypertensão craniana, de symptomas tabidos (abolição dos reflexos, desordens sensitivas etc.) no curso de tumores cerebraes, evolvendo com grande hypertensão. Nesses casos dá-se a penetração do liquido cephalo-rachidiano, sob pressão, no canal dural, donde a compressão do systema radicular posterior devido á infiltração dos feixes das raizes, posteriormente dos fasciculos, com compressão dos tubos nervosos e alargamento das bainhas (Parisot) (1), tudo resumido e integrado no syndromo da compressão radiculo-ganglionar. Precisamos distinguir as cousas e, sob o aspecto enganador dos signaes inherentes á hypertensão craniana, reconhecer os que denunciam a verdadeira localização morbida. Nem sempre conseguimos esse intento. Muitas vezes a hypertensão de tal maneira condiciona o quadro clinico, reproduzindo com tal exactidão a feição dos verdadeiros tumores, que o erro é inevitavel. E' o que acontece nos falsos tumores ligados á hydrocephalia interna, passiveis de remoção ou melhora pelas puncções repetidas. A hydrocephalia interna póde coexistir com os verdadeiros tumores cerebraes. E' observada em $50 \%$ dos tumores do mesencephalo (Vallobra) (1). Com mais baixa percentagem entram porventura os tumores de outras sédes, porque a localização mesencephalica, permittindo facilmente a occlusão do aqueducto de Silvio e a compressão da veia de Galeno, mais do que qualquer outra região encephalica, predispõe ao surto da hydrocephalia: a compressão da veia impede o curso livre do sangue dos plexos choroides para os seios venosos, dahi a plethora liquida nos plexos; fechado o aqueducto, como que aprisiona o liquido nos ventriculos superiores. (Valobra)

Creio que estaes bem penetrados da dissociação, apparentemente contradictoria, dos signaes verificados no doente e apparelhados para os interpretar em sua devida conta, tanto os que delatam a topographia exacta da lesão — base do cerebro á esquerda, comprimindo o facial e raiz sensitiva do trigemeo - como os que, superpostos á symptomatologia capital, realçam no quadro clinico a concomitancia da hypertensão craniana. Ainda na propria hypertensão e nos symptomas que lhe são correlatos - cephaléa e congestão accentuada das papillas - iremos encontrar apoio para o diagnostico de natureza do tumor Até aqui me tendes visto empregar a palavra tumor no sentido clinico - melhor diria lesão — sem

(1) RAYMOND - E'tudes de pathologie nerveuse - 1910.

(1) VALOBRA - I tumori del mesencephalo - 1910. 
prejulgar de sua natureza e sem mesmo adduzir provas aponadoras de sua existencia real. Mas, a cephaléa, as lesões do fundo dos olhos, (estase venosa e congestão papillar accentuada) a hypertensão, por integrarem, com os vomitos cerebraes, ausentes no caso, o syndromo hypertensivo, inseparavel do cortejo habitual dos tumores cerebraes, legitimam a presumpção de que se trate realmente de um tumor.

De que natureza será este? O diagnostico de natureza é sempre um jogo de probabilidades. Si attendermos á estatistica devemos pensar nos gliomas que são os tumores por excellencia do systema nervoso; si attendermos á historia e ao exame do idoente - que é um syphilitico ıconfesso - e que tem na formula cytologica (lymphocitose) e na Wassermann positiva no liquido cephalo-rachidiano o attestado da lues, todas as probabilidades serão em tfavior ıde um syphiloma (provavelmente gomma).

Não devemos nos esquecer, no entretanto, que Oppenheim accentia a frequencia idos sarcomas nos syphiliticos e que a hypothese de um tuberculo se ajusta bem á reacção cytologica lymphocytica do liquido cephalo-rachidiano.

\section{PROGNOSTICO}

Estabelecido o diagnostico nas bases em que me vistes erigil-o, c prognostico, que delle deriva, não póde seu auspicioso.

Dado que se trate de uma gomma poderá o tratamento especifico remover suas consequencias ou promover a cura completa? Creio que não; creio que com o tratamento alcançaremo algumas melhoras apenas, não obstante a observação clinica ter archivado já o quas' completo desvanecimento de gommas, sob a acção da cura especifica, e vou dizer-vos por que. Ha no nosso caso um elemento prognostico desfavoravel: é o ictus, com perda de consciencia, tonteiras etc., que abriu, por assim dizer, a scena morbida, começo agudo e provavelmente de origem vascular. Deveis saber que os vasos circumjacentes á gomma syphilitca são, com grande frequencia, séde de um processo que lhes interessa a endoarteria - a endoarterite syphilitica - que abre ensejo á hemorrhagias repetidas, creando, portanto, más condições de prognostico.

O tuberculo tambem é passivel de relativa cura espontanea pela calcificação, que permitte longa sobrevida, persistindo, porem, os eymptomas determinados.pella idestruição dos tecidos, e o individuo nessas condições deixa de ser um doente para ser um enfermo.

A evolução dos tumores cerebraes é muitas vezes longa, de 1, 2 cu mesmo 3 annos, conforme os casos, havendo em muitos doentes um periodo de acalmia devido á regressão de certos symptomas, que 
mais atormentam o doente, como a cephaléa, tornando-lhes a vida mais toleravel.

\title{
TRATAMENTO
}

Foi tentado o tratamento especifico pelas injecções de sáes mercuriaes insoluveis e de iodeto de sodio. Poderia ser experimentada a craniectomia descompressiva, tentando-se tambem fazer a extirᄁação do tumor. Entendo, porem, que os effeitos descompressivos talvez possam ser obtidos só pelas punç̧õess rachidianas repetidas. E. é o que vamos fazer.

Quanto á intervenção cirurgica extirpadora, não só o doente não se sujeita a esse tratamento, como, á vista das melhoras verificadas, acho de bom aviso tentarmos por mais tempo o tratamento mercurial, de cuja acção bemfazeja algo podemos esperar.

\section{Um caso de epilepsia Bravais-Jacksoniana}

\author{
POR \\ JOAQUIM PENNINO \\ DOUTORANDO EM MEDICINA
}

No dia 20 de maio p. p. deu entrada em nossa enfermaria um doente recommendado ao Prof. Rubião Meira pelo Dr. Luciano Gualberto. Trata-se do Sr. A. Marcello, com 22 annos de edade, brasileiro, solteiro, sapateiro residente em 's. Paulo.

Diz elle que o pae morreu de uma quéda a grande altura; a mãe está viva e gosa saude. Tem um irmão forte. Não se lembra de ter tido molestias proprias da infancia. Levou um tombo em creança $\theta$ em seguida, aos 2 annos, teve um ataque, segundo lhe diz a propria mãe. Depois disso lembra-se que só aos sete annos reappareceu o ataque, repetindo-se de 15 em 15 dias, mez em mez, e até 2 em 2 mezes. Aos 13 annos, depois de um desastre de automovel em que se lembra só ter fracturado o $1 \mid 3$ inferior do femur esquerdo, notou que os ataques se repetem com muita frequencia durante um certo tempo e como que desapparecem durante um periodo não muito longo.

Após uma pausa de 3 mezes os ataques se repetem todos că ãias com uma frequencia de 6 a 10 por dia.

Symptomatologia. 